\title{
DE REORGANISATIE VAN DE RECHTERLIJKE MACHT EN VAN DE RECHTSPLEGING DER KOLONIE CURAÇAO IN DE PRACTIJK ${ }^{1}$ )
}

\author{
DOOR
}

\author{
MR. F. G. SCHALKWIJK
}

Oud-Lid van het Hof van Justitie in Curaçao

In de rechtsgeschiedenis van de kolonie Curaçao zal de eerste November 1919 aangeteekend blijven als een belangrijke datum. Op dien dag werd immers een justitieele hervorming ingevoerd, welke in groote trekken hierop neerkomt, dat ontbonden werden de bestaande Kantongerechten der zes eilanden dier kolonie, zoomede de Raden van Justitie op St. Martin (Ned. Ged.) en St. Eustatius. Het geheele rechtsgebied werd opnieuw ingedeeld en wel in twee „Kantongerechten” ${ }^{2}$ ), één voor de Benedenwindsche eilanden - Curaçao, Aruba en Bonaire - en één voor de Bovenwindsche eilanden - St. Martin (Ned. Ged.), St Eustatius en Saba-, met bepaling, dat de betrekking van „Kantonrechter” zou worden waargenomen beurtelings door de individueele leden van het Hof van Justitie, met volledige competentie in civiele en strafzaken, voor de civiele zaken met eene bijna geheel nieuwe, op een weinig kostbare en snelle afdoening gerichte procedure, met beperking van 'sHofs functiën tot die louter

1) Aangaande de vó́rgeschiedenis van het nieuwe instituut zie Mr. B. de Gaay Fortman „De rechtsbedeeling op onze Bovenwindsche eilanden en de herziening van de rechterlijke macht en van de rechtspleging in de kolonie Curaçao" in de afl. Juni $19191 \mathrm{jg}$. $1^{\mathrm{e}}$ deel blz. 85 van dit tijdschrift.

$\left.{ }^{2}\right)$ De aanduiding van „Kantongerecht” is, in verband met de volledige competentie van de nieuwgeschapen rechterlijke autoriteit weinig eigenaardig en in ieder geval verwarrend: men had even goed kunnen spreken van „arrondissementen”. Liever bezig ik dan ook, waar mogelijk, de uitdrukking „Gerecht” en Rechter”. 
van een hooger-beroep-college, bij elk voorkomend appel samengesteld uit den President en twee leden, andere, dan van wien de beslissing in eersten aanleg afkomstig is. Het aantal leden van het Hof werd, in verband met deze reorganisatie, uitgebreid van twee tot vier leden, naast den President.

De vraag is: hoe ontwikkelde deze hervorming, waarbij verschillende twistpunten werden opgelost, waarover in het Moederland nog steeds strijd gevoerd wordt, zich in de practijk?

Wil men billijk oordeelen, dan behoort steeds in het oog te worden gehouden, dat de hervorming van het Curaçaosche rechtswezen haren oorsprong niet heeft gevonden in theoretische beschouwingen, doch voornamelijk de langzaam gerijpte vrucht is van de overtuiging, dat de rechtsbedeeling op de Bovenwindsche eilanden met hare uit leeken samengestelde Raden van Justitie op den duur niet onveranderd gehandhaafd kon blijven.

Ook hier moest. zooals zoo vaak elders. krachtens eene historische traditie in de rechtspraak, de vervanging van de ondeskundige dorpsgenooten door den rechtsgeleerden, onpartijdigen vakman eenmaal komen. Kan men den wetgever van Curaçao wellicht verwijten, dat hij te lang geaarzeld heeft met het invoeren eener hervorming, waarnaar men Bovenwinds al zoo lange jaren snakte en waarvan het uitblijven gevoeld werd als eene grievende achteruitzetting, de eer mag hem niet onthouden worden dat, toen het ondragelijke van den toestand ten langen leste werd ingezien, de verbetering niet gezocht werd in lapmiddelen, doch dat, met terzijdestelling van tal van locale bezwaren en persoonlijke gevoeligheden, de eenige en beste oplossing van het vraagstuk is aangedurfd door, wat de Bovenwindsche eilanden betreft, de detacheering bij toerbeurten van één der leden van het Hof van Justitie op St. Martin, met volledige competentie zoowel voor civiele als voor strafzaken, als ommegaande rechter voor de drie eilanden.

Vleiender oordeel over deze regeling is wellicht niet denkbaar, dan dat er onder de weldenkenden der Boven- 
windsche bevolking, aan welke, naast hare vele beminnelijke eigenschappen toch ook zekere neiging tot kritiek op elke bestuursdaad niet vreemd is, wel niet één is, die niet erkent, dat deze hervorming voor onze drie eilanden Boven den Wind, een zegen is gebleken. Wat in de eerste plaats is bedoeld met de uitzending van een jurist-rechter, een echten ,judge”, immers een goede, vooral een onpartijdige rechtspraak, dit doel is zeker bereikt. Aandoenlijk was het hoe, zoo dikwijls op mijne tochten op de eilanden tijdens mijn verblijf aldaar, eenvoudige lieden mij aanspraken om mij nog eens te betuigen hoe dankbaar zij „Queen Wilhelmina” en Haren raadgevers waren, omdat zij hun nu eens eindelijk een echten rechter gezonden hadden, staande buiten alle plaatselijke invloeden en van wien men zeker wist, dat hij tenminste ,,justice” doen zou. Gerechtigheid meer dan rechtsgeleerdheid was het, wat de bevolking van den rechter verlangde.

Proceszuchtig bleek zij allerminst. Wel steeg het aantal burgerlijke zaken na de invoering van het nieuwe instituut van den ommegaanden rechter, doch bij dit verschijnsel valt te bedenken, dat onder deze zaken veel oud zeer was, geschillen, welke reeds jaren lang hangende waren, welke men niet aan de plaatselijke Raden had durven toevertrouwen en waarvan men de berechting had uitgesteld tot de komst van den onafhankelijken, nieuwen functionaris. Toen ik het ambt van mijn voorganger - de eerste onder het nieuwe systeem - overnam, bewoog zich het aantal civiele zaken op St. Martin en St. Eustatius alweder in dalende lijn. Wat Saba betreft, de reis daarheen was gewoonlijk niet meer dan ,une promenade à Berlin"; gedurende de beide jaren, dat ik het eiland bezocht, werd slechts eenmaal een civiele zaak formeel aanhangig gemaakt en berecht.

De verdere werkzaamheden bestonden, als regel, alleen uit het verstrekken van adviezen en de behandeling van een of twee strafzaken. Trouwens, indien de bevolking proceszuchtig geweest ware, dan zouden twee oorzaken vooral haar hebben belet aan deze lust bot te vieren: vooreerst hare armoede, welke het aan partijen als regel 
onmogelijk maakte zelfs maar de geringe kosten van zegel voor het introductieve rekest en die van den deurwaarder te dragen en dan, in verband hiermede, het gebrek aan deskundige en betrouwbare rechtskundige hulp: gedurende mijn ambtstijd was er op geen der. drie eilanden een practizijn - Westindische benaming voor den $\mathrm{Ne}$ derlandschen advocaat- - gevestigd. Onder deze omstandigheden is het begrijpelijk, dat de bevolking gretig gebruik maakte van de door den rechter geboden gelegenheid om haar in raadkamer van voorlichting te dienen en dat zich naast en over het civiele geding heen al spoedig een practijk van kostelooze consultatieve rechtsbijstand ontwikkelde, welke van den tijd en de aandacht van den Rechter niet weinig vergde. Tegengegaan heb ik deze practijk niet: zij was een normaal gevolg van de geschetste abnormale omstandigheden. En bovendien, ik leerde op die wijze de bevolking en haar belangen, haar lief en leed in vollen omvang kennen: de taak van den ommegaanden rechter als vrederechter is op de Bovenwindsche Eilanden zeker niet de minst aantrekkelijke van het ambt!

Met de strafzaken was een dergelijke gemoedelijke wijze van werken natuurlijk niet mogelijk: zij zou inderdaad hoogst ongewenscht geweest zijn. Ook het aantal strafzaken bewoog zich na de komst van den ommegaanden rechter dadelijk in stijgende lijn. Men zal in dit verschijnsel wel in de eerste plaats het gevolg hebben te zien van eene meer vruchtbare samenwerking van het Openbaar Ministerie met den deskundigen, onpartijdigen en belangstellenden beroepsrechter en de zekerheid van eene behoorlijke behandeling der voorgebrachte zaken, zonder aanzien van de bijzondere belangen van de leden van het rechterlijk college, zooals vroeger scheen voor te komen. De sterke toeneming van de veroordeelingen op St. Martin wegens smokkelhandel van gedistilleerd, spreekt hier boekdeelen.

Alles bijeengenomen, komt het mij voor, dat de deskundige ommegaande rechter voor de Bovenwindsche Eilanden als een gevestigd en onmisbaar instituut mag worden 
beschouwd, dat aan de verwachtingen heeft voldaan. Enkele verbeteringen zijn intusschen nog mogelijk. Zoo is de detacheeringstermijn van één jaar voor den rechter veel te kort, aangezien hij op de Bovenwindsche Eilanden te doen heeft met eene bevolking en met toestanden, wier eigenaardigheden tijd kosten om deze te leeren kennen en te begrijpen, terwijl ook het gebruik van het Engelsch als voertaal, ook bij de rechtsspraak, den Nederlandschen rechter niet dadelijk gemakkelijk valt. Het was om deze reden dat ik zelf na ommekomst van mijn ambtelijk jaar het betreurende, dat mijne juist rijpende ervaring, door terugkeer naar Curaçao weder verloren zou gaan, vergunning vroeg en verkreeg, om nog een jaar „Boven" te blijven. Intusschen, wat ik voor mijzelf als een voorrecht beschouwde, kan een bezwaar zijn voor de andere, vooral voor de van huis uit Curaçaosche leden van het Hof van Justitie, die te Willemstad blijvend gevestigd zijn en die over de Bovenwindsche Eilanden ongeveer plegen te denken als Ovidius over Tomi. M.i. ligt de oplossing voor de hand den ommegaanden rechter niet langer aan te wijzen uit de leden van het Hof van Justitie, doch door het ambt meer blijvend te doen bekleeden door een direct uit het Moederland gedetacheerd jurist met den titel van buitengewoon lid van het Hof van Justitie, aan te wijzen bijv. voor een drietal jaren, op eene bezoldiging, welke met het oog op den duren levensstandaard te St. Martin en het aanzien van den rechter in een vrij internationaal milieu op niet minder te bepalen is dan op een 9000 gulden per jaar. Voor plaatselijke invloeden behoeft een onafhankelijke, Europeesche functionaris niet bevreesd te zijn en bij juiste voorlichting, maak ik mij sterk, dat het niet moeilijk zal behoeven te vallen onder hen, die gaarne hun blik willen verruimen, personen bereid te vinden tot het bekleeden van een ambt, waarin zij - indien het hun gaat gelijk mij — zeker niet de gemakkelijkste, maar wellicht toch de meest opmerkelijke jaren van hun leven zullen doorbrengen.

Voor de Benedenwindsche Eilanden heeft de reorgani- 


\section{RECHTSPLEGING DER KOLONIE CURAÇAO}

satie na hare invoering reeds geschiedenis gemaakt: was oorspronkelijk bepaald, dat ook voor dit „Kantongerecht' even als voor het Bovenwindsche één lid van het Hof als rechter zou worden aangewezen, met de twee overige leden van het Hof als plaatsvervangers, doch alleen voor het eiland Curaçao, de collegialiteit heeft reeds spoedig doen inzien, dat het moeilijk aanging één der ambtgenooten de beide eilanden te doen bereizen en de overigen rustig te Willemstad te laten. A l'instar van enkele groote kantongerechten in Holland is toen bepaald, dat alle drie te Willemstad gevestigde leden van het Hof tezamen het ambt van Rechter voor de Benedenwindsche Eilanden met onderlinge verdeeling der werkzaamheden, zouden waarnemen, en nog een stap verder is men gegaan door, toen bleek, dat op deze wijze de President vrijwel tot een ornament zonder nut of doel was teruggebracht, te bepalen, dat ook deze, doch dan alleen op Curaçao, als rechter zou kunnen functioneeren.

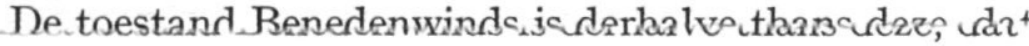
op Curaçao de President en drie leden van het Hof voor het werk aldaar beschikbaar zijn en deze laatste drie voor het bereizen van Aruba en Bonaire. Voor Curaçao is door de geschetste arbeidsverdeeling het ambt van lid van het Hof vrijwel gebleven wat het was, eene sinecure: de civiele rol bepaalt zich voornamelijk tot verstekzaken, terwijl de cijfers aantoonen, dat voor Curaçao de toestand deze is, dat de zaken, welke vroeger door den eenen ongegradueerden Kantonrechter behandeld plachten te worden, thans voor rekening komen van de vier juristen van het Hof ${ }^{1}$ ).

De strafzaken bedragen als regel niet meer dan een

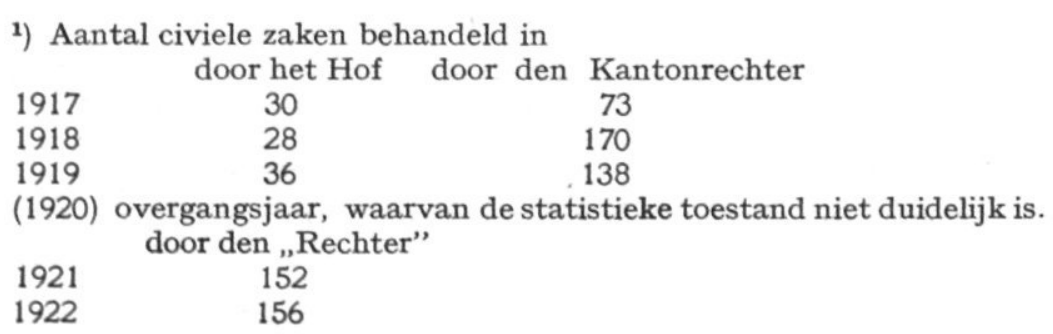


twaalf per week, te verdeelen over twee zittingen en twee leden. Het aantal hooger beroepen van den eenen rechter op de drie anderen welke dan tezamen het oude Hof formeeren, is voor de strafzaken stijgende doch gering in getal $^{\mathbf{1}}$ ).

Wat Bonaire en Aruba betreft pleegt het eerstgenoemde eiland bij de viermaandelijksche bezoeken bijna geen zaken op te leveren; op Aruba kan de ommegaande rechter het, vooral met strafzaken, gedurende den uitteraard beperkten tijd van zijn bezoek, vrij volhandig hebben.

Toch zou, telden andere factoren niet mede, het Benedenwindsche Gerecht het zonder veel moeite, evenals het Bovenwindsche, met één rechter kunnen stellen, ware het niet, dat de ontwerper der nieuwe organisatie- en dit niet geheel ten onrechte - blijkbaar van oordeel is geweest, dat het moeilijk aangaat het hoofdeiland Curaçao gedurende de ambtsreizen naar de beide Eilanden, tijdelijk zonder rechter te laten, terwijl bovendien drie der te Willemstad gevestigde leden van het Hof noodig waren om daaruit een hooger beroepscollege te vormen. Doch daarbij had men het moeten laten: het vierde lid beteekent, nu ook de President voor Curaçao beschikbaar is, overdaad en men heeft m.i. kort geleden, toen er eene vacature in het Hof was, eene schoone kans tot bezuiniging laten voorbijgaan door die vierde plaats wederom aan te vullen, in stede van in voorkomende gevallen de hulp in te roepen van één der plaatsvervangende leden van het Hof, in welker keuze men den laatsten tijd bijzonder gelukkig is geweest.

Voor het eiland Curaçao is er van den beginne af weinig behoefte aan veranderingen geweest: in plaats van den Rechter met volledige competentie van nu, stond toen de klassieke Kantonrechter voor de zaken van geringe beteekenis, voor het overige kon men bij het Hof terecht.

$\begin{array}{rrrc}\text { 1) hooger beroep } & & \\ \text { civiele zaken } & \text { strafzaken } & \text { Totaal. } \\ \text { In } 1920 & 3 & 2 & 5 \\ 1921 & 2 & 5 & 7 \\ 1922 & 1 & 4 & 5 \\ 1923 & 1 & 11 & 12\end{array}$


Doch voor Bonaire en Aruba beteekent de nieuwe regeling, evenals voor de Bovenwindsche Eilanden, grootendeels winst, in zooverre als de leekenrechtspraak van den als regel wenig deskundigen Kantonrechter vervangen is door den jurist met volledige competentie. En wat nog meer beteekent, voor de vroegere „Hofzaken” behoeven de bewoners der beide eilanden thans geen bezwaarlijke reis meer te maken naar Curaçao; echtscheidingen, verbeteringen van akten van den burgerlijken stand bijv. kunnen thans op het eiland zelve door den ommegaanden rechter geregeld en vlug worden afgedaan, met vermijding van de vaak nog hooge kosten aan praktizijn en vergoeding aan getuigen. Wat de strafzaken aangaat, wordt door de behandeling, thans dus ook van misdrijven ter plaatse, vooral den getuigen, die nu niet meer naar Curaçao behoeven te gaan zooals vroeger bij de behandeling voor het Hof, heel wat geld en tijdverlies bespaard.

Daar staan enkele bezwaren tegenover: voor kleine zaken, welke vroeger dadelijk door den Kantonrechter werden afgedaan, voor de vrijwillige rechtspraak ook, moet men nu als regel wachten tot het viermaandelijksch bezoek van den ommegaanden rechter. Doch voor een deel is dit bezwaar in de practijk ondervangen door den waarnemenden Kantonrechter, een ingezetene van het Eiland, bij afspraak bevoegd te verklaren tot afdoening van eenvoudige voogdijzaakjes, van scheepsverklaringen en dergelijke. Bedenkelijker is de noodzakelijkheid soms, om de behandeling van een belangrijke strafzaak, waarin bijv. één der getuigen niet verschenen is, weder vier maanden te moeten uitstellen". Ook met het rechter-commissariaat moet er, behalve op Curaçao, Bovenwinds zoowel als Benedenwinds geschipperd worden. Die nieuwe wet bepaalt, dat de rechter in strafzaken zelf de taak van rechter-commissaris vervulle, een voorschrift dat, bij het opgeven van collegiale strafrechtspraak, voor de hand lag. Doch de moeilijkheid voor den rechter om zich spoedig en voor langeren tijd van zijn standplaats te verwijderen, riep de praktijk in het leven om de taak van rechter- commissaris zooveel mogelijk op de schouders te leg- 
gen van den op het eiland gevestigden waarnemenden Kantonrechter, een systeem, dat zeker het voordeel heeft, dat op deze wijze naar goede traditie, de rechter, die de instructie geleid heeft, een ander is dan die de zaak berecht. Alleen op Curaçao, met zijn opeenhooping van kantonrechters, ontstond de gewoonte, dat het rechtercommissariaat wordt waargenomen door één der leden, meestal den President.

Zoo zijn er, naar ik aantoonde, enkele schaduwzijden, doch in het algemeen genomen, had ik den indruk, dat althans de bevolking van Aruba en Bonaire, welke van den nieuwen toestand tastbare voordeelen heeft, niet ontevreden is.

Een andere vraag is het, of de leden van het van huis uit zeer onbeweeglijke, te Willemstad gevestigde Hof van Justitie, ingenomen waren met de nieuwe verplichting enkele malen in het jaar hun rustige rust te moeten verbreken door als reizend rechter den boer op te gaan.

Het antwoord is streng individueel. Zelf heb ik deze verplichting zoowel daar „Boven” als „Beneden” gevoeld als eene welkome gelegenheid om op deze wijze de kolonie in haar geheel en met al haar verschillende bevolkingslagen te leeren kennen. Maar ik moet bekennen mij volkomen te kunnen indenken in de bezwaren van die ambtgenooten voor wie het reizen in ongemakkelijke, zeeziekte verwekkende schoeners en het verblijf in de dikwijls al te sober ingerichte gouvermentslogeergebouwen het bezoek der Eilanden maakt tot een zwaar drukkende plicht. Onder de huidige slechte tijdsomstandigheden is het mogelijk voor elk ambt een vervuller te vinden, doch wanneer de malaise wegtrekt en het aanbod van krachten voor de rechterlijke macht in Curaçao weder de minimale afmetingen aanneemt van daarvóór, dan zal denkbaar zijn, dat het tegenwoordige nomadenkarakter van het lidmaatschap van het Hof de aanvulling van vacaturen niet gemakkelijk zal maken.

Blijkt intusschen de tegenwoordige organisatie ook voor de Benedenwindsche eilanden op den duur uitvoerbaar, ook wat betreft de uitzending van rechterlijk per- 
soneel, dan zal te zijner tijd de vraag onder de oogen moeten worden gezien, in hoeverre, naast de gegradueerde rechters, op den duur ook in het openbaar Ministerie het leekenelement behouden kan blijven. M.i. bestaat op zich zelf tegen de medewerking van ongegradueerden in het Openbaar Ministerie geen bezwaar: wie toch zou meenen dat bijv. de behandeling der strafzaken te Willemstad niet tot haar recht komt, omdat de huidige Advocaat-Generaal, wiens uitnemende kennis van het burgerlijk- en militair strafrecht door niemand betwijfeld wordt, toevallig een wetenschappelijke titel mist?

De bedenkingen op dit punt moeten dan ook m.i. veeleer gericht worden tegen het feit, dat op de andere eilanden dan Curaçao als regel tot waarneming van het Openbaar Ministerie worden aangewezen de Ontvangers, jongelieden, over wier intelligentie, toewijding en medewerking niet met genoeg lof kan gesproken worden, doch voor wie de justitieele functie, ondanks dat alles, slechts eene nevenfunctie is. En toch - men verlieze dit niet uit het oog - is onder de nieuwe organisatie aan hen de nasporing en vervolging opgedragen, niet alleen van de meer eenvoudige overtredingen, doch ook van de zwaarste misdrijven en dat als regel onder geen andere leiding dan van den met werk overkropten Gezaghebber en den ondeskundigen waarnemenden rechter-commissaris. Te kwader ure heeft men dan ook voor de Bovenwindsche Eilanden gebroken met het oorspronkelijk systeem, waaronder de voor zijn taak bijzonder goed berekende beroeps-Ambtenaar bij het Openbaar Ministerie van St. Martin ook voor de beide andere eilanden daar bevoegd was en den Rechter bij zijn reizen vergezelde. Voor de Benedenwindsche Eilanden is er in ieder geval op den duur geen enkele reden, dat de Advocaat-Generaal bij het Hof niet eveneens den Rechter naar Aruba en Bonaire vergezelt om de daar dan te behandelen strafzaken behoorlijk geinstrueerd te kunnen voorbrengen. De zelfstandigheid van het Openbaar-Ministerie tegenover den Rechter, waaraan de tegẻnwoordige Procureur-Generaal bij het Hof van Justitie terecht zooveel waarde hecht, kan daardoor niet anders 
dan gebaat zijn. Tijdens de afwezigheid van den Advocaat Generaal van het Eiland Curaçao, zullen de strafzittingen daar kunnen worden waargenomen bijv. door den Procureur-Generaal. Ik heb het steeds betreurd, dat de uitnemende kracht, die het Openbaar Ministerie van Curaçao in zijn eenigen jurist bezit, door administratieve bezigheden bijna geheel van het justitieele werk en vooral van de medewerking aan de rechtspraak wordt afgetrokken.

En een bepaalden achteruitgang in den tegenwoordigen toestand acht ik het dat ook de medewerking van het Openbaar-Ministerie aan de civiele rechtspraak geheel is afgeschaft, op grond vermoedelijk van het m.i. als dan zeer zwakke argument, dat het Kantongerecht die medewerking nu eenmaal niet kent, zwak, omdat dan vergeten wordt, dat het tegenwoordige Kantongerecht met het oude instituut slechts den naam gemeen heeft. De regeling van het hooger beroep van alle bslissingen van den eersten rechter, lid van het Hof van Justitie, op een telkens ad hoc gevormd „Hof”, bestaande uit drie der op Curaçao zetelende ambtgenooten, die over de zaak niet gezeten hebben, heeft geen onverdeelde instemming gevonden; bij de ambtgenooten niet, omdat het niet aangenaam wordt gevonden elkanders arbeid te beoordeelen, bij het publiek niet, omdat men daar vreest voor de neiging om uit collegiale overwegingen de beslissingen in eersten aanleg zooveel mogelijk te bevestigen. Deze regeling is overigens geen novum: zij bestaat naar ik meen, in de Engelsche Westindische Koloniën en, naar ik zeker weet, in Suriname voor de strafvonnissen van de ommegaande rechters - leden van het Hof van Justitie. Ideaal is zij zeker niet, maar uit noodzaak, bij beperking van het rechterlijk personeel geboren, heeft zij althans het voordeel, dat thans gelegenheid bestaat om over elke zaak in twee instanties te doen oordeelen. Dat was vroeger in $\mathrm{Cu}-$ raçao met de „Hofzaken” niet het geval.

Met de wijziging van de rechterlijke organisatie is die van de rechtspleging gepaard gegaan, welke voornamelijk voor de behandeling van burgerlijke zaken van be- 
lang is: de verplichte rechtsbijstand der praktizijns werd, naar men weet, afgeschaft; partijen verschijnen in persoon dan wel bij gemachtigde ter zitting, de zaak wordt niet meer bij dagvaarding, doch bij verzoekschrift aanhangig gemaakt, hetwelk, wat den materieelen inhoud betreft, slechts behoeft te bevatten, eene aanduiding van het onderwerp der vordering en wat gevorderd wordt. De Rechter bepaalt dag en uur der behandeling en roept zelf partijen met hunne getuigen en bewijsstukken op; hij mag bij de behandeling der zaak de noodige voorlichting geven haar ondervragen en zelfs opmerkzaam maken op de rechts- en bewijsmiddelen, welke zij kunnen aanvoeren. De behandeling geschiedt voor alle zaken mondeling met zoo mogelijk dadelijk uitspraak.

Praeparatoire en interlocutoire vonnissen worden niet afzonderlijk opgemaakt, doch alleen op het proces-verbaal der zitting aangeteekend.

Ziedaar enkele trekken der Curaçaosche burgerlijke rechtsvordering, met als doel eenvoudige goedkoope en snelle rechtspraak. Bij de beantwoording der vraag of dit doel bereikt is, valt te herinneren, dat het grootste deel der te behandelen civiele zaken naar haar karakter als regel niet anders zijn dan de vroegere „Kantongerechtszaken" en derhalve ook onder den ouden plooi behandeld zouden zijn volgens den vroegeren met het Moederland eenvormige Kantongerechtprocedure, waarvan het werkelijke verschil met de huidige Curaçaosche meer schijn dan wezen is: processueel toch maakt het weinig onderscheid of het introductieve stuk dagvaarding dan wel „verzoekschrift" wordt genoemd. Komt thans in Curaçao voor middelen en onderwerp van den eisch eene aanduiding van het onderwerp in de plaats, ook de inhoud van de dagvaarding voor het Kantongerecht pleegt nu eenmaal uitteraard sober te zijn, terwijl ook de oproeping door den Rechter instede van door de eischende partij niet veel verschil maakt, aangezien deze, als regel, voor de behandeling geen ander tijdstip pleegt aan te wijzen dan den gewonen dag en tijd voor de civiele zaken bestemd. De mondelinge behandeling heeft de nieuwe procedure 
met de vroegere kantonale gemeen; zij gaf den Kantonrechter, wien dit in zijn aard ligt, gelegenheid te over, de meestal ondeskundige partijen door gemoedelijken raad wat op weg te helpen. Heeft de nieuwe procedure derhalve beteekenis, dan moet dit zijn voor de vroegere HofRechtbankzaken, welker behandeling schriftelijk placht te geschieden. Het is jammer, dat de Curaçaosche praktijk op dit punt tot heden weinig houvast biedt, aangezien het aantal belangrijke civiele zaken, dat de laatste jaren aan het oordeel van den Curaçaoschen rechter onderworpen werd, slechts gering is. Voorzoover een oordeel mogelijk is, zou het mij willen voorkomen, dat de praktijk tot dusverre heeft uitgewezen, dat de mondelinge behandeling voor alle civiele zaken, dus ook voor die met ingewikkeld feitenmateriaal niet geschikt, is. Het zonder beperking en leiddraad heen en weer praten, het ineen vloeien van mondelinge „,conclusies” en ,pleidooi” verheldert het inzicht in de feiten en het rechtspunt allerminst en de neiging bestaat om tot schriftelijke debatten terug te keeren, zonder de voordeelen der strengere, meer vormelijke rechtbank procedure. Evenmin had ik den indruk, dat voor de meer ingewikkelde zaken de mondelinge procedure eene snellere afdoening verzekert dan de vroegere schriftelijke voor het Hof. Alleen het voorschrift, dat voor praeparatoire en interlocutoire vonnissen kan worden volstaan met het maken van een aanteekening op het proces-verbaal der zitting, heb ik als een voordeel gevoeld bepaaldelijk bij het opleggen van getuigenbewijs en van eeden, aangezien toch in de kantonale praktijk het schriftelijk vonnis achter het mondelinge pleegt aan te komen.

Tegenover dit betrekkelijk geringe voordeel boekt de nieuwe procedure in haar debet de volledige afschaffing van de verplichte rechtsbijstand der praktizijns, een maatregel, welke bepaaldelijk Curaçao treft, het eenige eiland, waar op het oogenblik praktizijns gevestigd zijn en waar hun bijstand onder de oude rechtsvordering voor het Hof gevorderd werd. Naast een te ver gedreven zucht tot eenvormigheid, heeft ook het kostenelement hier waarschijnlijk den doorslag gegeven. $\mathrm{Al}$ is er inderdaad nu en 
dan door de rechtzoekenden over hooge praktizijnsrekeningen geklaagd, thans schijnt de klacht der praktizijns niet ongegrond, dat, nu een ieder bevoegd is als gemachtigde voor het Gerecht op te treden, het bij de wet geregelde ambt van praktizijn alleen verplichtingen oplegt en geen rechten schept. Op die wijze ontbreekt op den duur elke prikkel voor jongelieden, die zich tot de balie gevoelen aangetrokken, zich de kosten en moeite te getroosten om zich voor het praktizijnsambt te bekwamen; stelt men te Curaçao prijs op een rechtsgeleerden stand, en wil men vermijden, dat de behandeling van rechtszaken op den duur geheel in handen komt van onbekwame zaakwaarnemers, op wie geen toezicht mogelijk is, dan zal de huidige regeling op dit punt - althans voor Curaçao niet ongewijzigd mogen blijven. De afschaffing van het instituut der toegewezen raadslieden - praktizijns in strafzaken - eveneens een gevolg van de zucht tot uniformiteit - hangt hiermede nauw samen. Het is thans

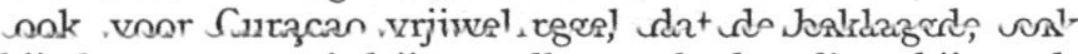
bij de zwaarste misdrijven, elken rechtskundigen bijstand moet ontberen. Deze toestand - in tegenstelling met de behandeling der delicten voor den Krijgsraad - mag, althans op Curaçao, niet blijven bestaan: voor de beklaagden niet, doch evenmin voor den Rechter, wiens taak en verantwoordelijkheid niet weinig wordt verzwaard bij de berechting van beklaagden, die niet in staat zijn van de aan de verdediging toegekende rechten gebruik te maken. De alleensprekende rechter bovenal, die toch reeds de adviezen van zijn ambtgenooten mist, heeft behoefte aan de voorlichting eener goed toegeruste verdediging.

Overigens acht ik een oordeel over het instituut van den unus judex voor alle zaken, in hoofdzaak individueel. In het Moederland ontwikkelt zich een gelukkige middenpraktijk door de mogelijkheid civiele rechtbankzaken van minder ingewikkelden aard naar een enkelvoudige kamer te verwijzen; de politierechter vervult voor het strafrecht eenigermate dezelfde rol. De Curaçaosche regeling doet trouwens niets ander dan, door noodzaak gedwongen, met gedurfdheid de lijn van den geschetsen 
middenweg doortrekken. De overweging, dat collegiale juristenrechtspraak voor de geheele kolonie Curaçao toch een onbereikbaar ideaal is, heeft er overigens waarschijnlijk toe medegewerkt, dat tot dusverre door alle leden van het Hof als alleensprekende rechters met opgewektheid eene taak aanvaard is, welke onder andere omstandigheden wellicht tot bezwaren aanleiding gegeven zou hebben. De verkregen ervaring is echter van dien aard, dat zij voor verderen uitbouw van het instituut van den unus judex gezond materiaal oplevert.

Vat ik het vorenstaande samen, dan kan het oordeel over de nieuwe justitieele hervorming in Curaçao bijna onverdeeld gunstig luiden voor de Bovenwindsche Eilanden, terwijl ook Aruba en Bonaire, die eveneens juristenrechtspraak hebben gekregen, in eigen huis, in het algemeen reden tot tevredenheid hebben. Curaçao daarentegen heeft, als gevolg van eene te vergedreven uniformiteit ten koste van hare zustereilanden, ongetwijfeld in veel opzichten ingeboet. In véle opzichten, niet in alle. Gewonnen heeft het, doordat thans op Curaçao - anders dan vroeger voor het Hof - eene behandeling in twee instanties voor alle zaken mogelijk is geworden, terwijl ook voor de leden van het Hof een werkkring is geopend met wijder perspectieven. Doch daar staat tegenover, dat voor het werk van den vroegeren ongegradueerden Kantonrechter thans vier juristen in het geweer geroepen worden, Ook de verplichte mondelinge behandeling van alle civiele zaken, vooral de besproken achteruitzetting van den praktizijnsstand met hare dadelijke gevolgen in strafzaken en de nog stiefmoederlijke inrichting van het Openbaar Ministerie, vormen ernstige schaduwzijden van het nieuwe instituut. M.i. zal het voor het Hof van Justitie, waaraan ook de taak is opgedragen als "Commissie van Wetgeving" den Gouverneur te dienen van advies over onderwerpen van legislatieven aard en waarin ook de gereorganiseerde rechtspraak meer dan eens een punt van bespreking heeft uitgemaakt, eene aantrekkelijke taak zijn zijne aandacht te richten op de vraag, in hoeverre het mogelijk zal zijn met behoud van het goede, dat 
de nieuwe toestand den anderen eilanden geschonken heeft, aan de belangen van het hoofdeiland op justitieel gebied meer recht te doen wedervaren.

$\mathrm{De}$ oeconomische en commercieele opbloei, welke $\mathrm{Cu}$ raçao thans beleeft en welke dit eiland maken tot een haven van internationale beteekenis, stellen ook aan de rechtsbedeeling daar op den duur bijzondere eischen.

Paramaribo, 1924. 